
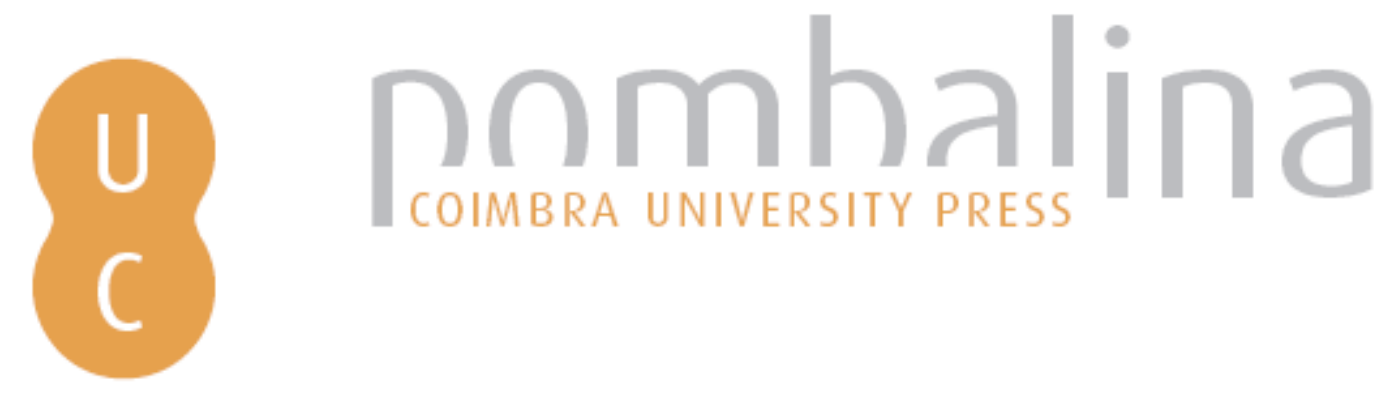

Interações entre águas e sedimentos das lagunas do Mangal do Lobito (Angola)

Autor(es): $\quad$ Guerreiro, R.; Dinis, P. A.; Silva, M. M. V. G.

Publicado por: Imprensa da Universidade de Coimbra

URL

persistente: $\quad$ URI:http://hdl.handle.net/10316.2/31472

DOI: $\quad$ DOI:http://dx.doi.org/10.14195/978-989-26-0534-0_39

Accessed : $\quad$ 26-Apr-2023 16:12:24

A navegação consulta e descarregamento dos títulos inseridos nas Bibliotecas Digitais UC Digitalis, UC Pombalina e UC Impactum, pressupõem a aceitação plena e sem reservas dos Termos e Condições de Uso destas Bibliotecas Digitais, disponíveis em https://digitalis.uc.pt/pt-pt/termos.

Conforme exposto nos referidos Termos e Condições de Uso, o descarregamento de títulos de acesso restrito requer uma licença válida de autorização devendo o utilizador aceder ao(s) documento(s) a partir de um endereço de IP da instituição detentora da supramencionada licença.

Ao utilizador é apenas permitido o descarregamento para uso pessoal, pelo que o emprego do(s) título(s) descarregado(s) para outro fim, designadamente comercial, carece de autorização do respetivo autor ou editor da obra.

Na medida em que todas as obras da UC Digitalis se encontram protegidas pelo Código do Direito de Autor e Direitos Conexos e demais legislação aplicável, toda a cópia, parcial ou total, deste documento, nos casos em que é legalmente admitida, deverá conter ou fazer-se acompanhar por este aviso. 



\title{
INTERAÇÓES ENTRE ÁGUAS E SEDIMENTOS DAS LAGUNAS DO MANGAL DO LOBITO (ANGOLA)
}

\author{
WATER-SEDIMENT INTERACTION IN THE \\ MANGAL DO LOBITO LAGOONS (ANGOLA)
}

R. Guerreiro' , P. A. Dinis² \& M. M. V. G. Silva ${ }^{3}$

\begin{abstract}
Resumo - Neste trabalho estudámos águas e sedimentos de lagunas do Mangal do Lobito. Em 8 locais previamente selecionados, procedeu-se a uma campanha de amostragem de sedimentos (novembro de 2009) e duas de águas (novembro de 2009 e maio de 2010). Nas amostras de água foram analisados parâmetros físico-químicos (temperatura, $\mathrm{pH}$, Eh, condutividade elétrica, oxigénio dissolvido, fosfato, nitrito, $\mathrm{Fe}$ e $\mathrm{Cu}$ ). Nos sedimentos fez-se a determinação da granulometria, mineralogia das fraçóes inferiores a $2 \mathrm{~mm}, 0,063 \mathrm{~mm}, 0,032 \mathrm{~mm}$ e $0,002 \mathrm{~mm}$ e da concentração em Fe e Cu. Fez-se uma avaliação da variabilidade espacial e temporal das propriedades selecionadas. Posteriormente, analisaram-se as relações entre as propriedades das águas e dos sedimentos visando identificar as possíveis interaçóes nas lagunas. As águas das lagunas são tendencialmente mais básicas, mais salinas, têm maiores concentraçốes de $\mathrm{Fe}$ e $\mathrm{Cu}$ e menor oxigénio dissolvido que as águas do oceano. Os teores de Fe e Cu são maiores na estação seca, refletindo intensa evaporação, ao passo que os teores de fosfato e nitrito tendem a ser maiores durante a estação húmida, em resposta à lavagem dos campos e áreas urbanas envolventes. Os sedimentos colhidos em zonas mais interiores das lagunas são tendencialmente mais finos e apresentam maiores quantidades de carbonatos, ao passo que os mais exteriores são mais grosseiros e mais ricos em silicatos. Existe uma correlação entre o Eh da água e a concentração de hematite nas frações mais finas, sugerindo alguma precipitação in-situ deste mineral.
\end{abstract}

\footnotetext{
1 Lubango; reny_f@hotmail.com

2 Departamento de Ciências da Terra da Universidade de Coimbra e IMAR-CMA; pdinis@dct.uc.pt

3 Departamento de Ciências da Terra da Universidade de Coimbra e Centro de Geociências, FCTUC; mmvsilva@ci.uc.pt
} 
Palavras-chave - Água; Sedimento; Mineralogia; Granulometria; Geoquímica; Mangal do Lobito

Abstract - In this work we study waters and sediments from lagoons of the mangrove of Lobito. A sediment sampling campaign (November 2009) and two water sampling campaigns (November 2009 and May 2010) were carried out in 8 site previously selected. For each water sample we measured physical-chemical properties (temperature, $p H$, Eh, electric conductivity, dissolved oxygen, phosphate, nitrite, $\mathrm{Fe}$ and $\mathrm{Cu}$ ). The grain-size, mineralogy of different sizefractions (fractions finer than $2 \mathrm{~mm}, 0.063 \mathrm{~mm}, 0.032 \mathrm{~mm}$ and $0.002 \mathrm{~mm}$ ) and Fe and Cu contents were determined in each sediment sample. An evaluation of the spatial and seasonal variability of the selected features was conducted. Later, the relations between water and sediment were analyzed in order to understand their possible inter-actions. The lagoon waters tend to be more basic, more saline, have higher Fe and Cu concentrations and less dissolved oxygen than the ocean water. The content of $F e$ and $C u$ are greater in the dry season, reflecting intense evaporation, while the levels of nitrite and phosphate tend to be higher during the rainy season, due to washing of surrounding fields and urban areas. Sediments collected from the inner areas of the lagoon tend to be finer and have higher amounts of carbonates, while the sediments from outer areas are coarser and richer in silicates. There is a correlation between the water Eh and the concentration of hematite in the finer grain-size fractions, suggesting some in-situ precipitation of this mineral.

Keywords - Water; Sediment; Grain-size; Mineralogy; Geochemistry; Mangrove of Lobito

\section{1 - Introduçáo}

A zona que hoje recebe a designação de Mangal do Lobito está situada na faixa costeira da Província de Benguela, município do Lobito, desenvolvendo-se na bordadura das acumulaçóes sedimentares provenientes do delta do Catumbela. Está limitada pela restinga do Lobito, a norte, pela Baía do Lobito, a nordeste, e por sedimentos associados ao delta do Catumbela, a sul. Esta zona não tem as características, em particular de vegetação, que tipificam os mangais. Encontram-se no Lobito corpos lagunares muito pouco profundos, sob grande pressão urbana e sem claros testemunhos de vegetação arbórea adaptada às condiçóes de elevada salinidade. A destruiçáo do Mangal do Lobito terá acompanhado o desenvolvimento da cidade de Lobito, que começou no início do século xx, com o porto do Lobito e o caminho-de-ferro de Benguela. A área do Mangal, na década de 1950, ainda era bastante alargada, observando-se então zonas habitacionais relativamente restritas e limitadas a setores nas proximidades das principais vias de comunicação (GUERREIRO, 2010). Mas já então a área estava muito influenciada por modificaçôes antrópicas (salinas, vias de comunicação, etc.). Hoje, temos uma área onde a pressão urbanística se tem alargado para pontos mais próximos de zonas húmidas. A intensa ocupação humana é responsável por uma degradação ambiental cujo diagnóstico ainda é desconhecido.

Este trabalho tem como objetivo apresentar algumas características das águas e sedimentos das lagunas do Mangal do Lobito e proceder a uma análise das relaçóes encontradas entre os dois. Os resultados obtidos contribuem para o diagnóstico das condiçôes ambientais observadas presentemente no Mangal. 


\section{2 - Metodologia}

Foram feitas duas campanhas de amostragem de água em oito locais previamente escolhidos (Fig. 1). Uma em novembro de 2009, antes da estação das chuvas e outra em maio de 2010, após a estação das chuvas. Para cada ponto de amostragem mediu-se "in situ" o $\mathrm{pH}$, Eh $(\mathrm{mV})$, a condutividade elétrica $(\mathrm{mS} / \mathrm{cm})$, a salinidade (ppt), a temperatura $\left({ }^{\circ} \mathrm{C}\right.$ ), o oxigénio dissolvido (em \% saturação e em $\mathrm{mg} / \mathrm{L}$ ) e o total de sais dissolvidos (TSD, em mg/L). Para tal, usou-se o equipamento Multiparâmetros Hanna (modelo HI 9828), cuja precisão é $\pm 10 \%$. Foram colhidas amostras de água e nelas foram doseados $\mathrm{Fe}, \mathrm{NH}_{3}$, $\mathrm{K}, \mathrm{Cu}, \mathrm{Cr}^{6+}, \mathrm{NO}_{2}, \mathrm{NO}_{3}, \mathrm{PO}_{4}, \mathrm{Mg}, \mathrm{Cl}$ e $\mathrm{SO}_{4}$, usando um fotómetro de bancada de UVvisível, da marca Hanna, modelo HI83200, cuja precisão ronda 4-10\%.

Colheram-se amostras de sedimentos, nos mesmos locais e momentos em que se fez a amostragem de águas durante a campanha de novembro de 2009, que foram secas ao ar livre, devidamente cobertas com papel e depois sujeitas a tratamento laboratorial para determinação das características texturais, mineralógicas e geoquímicas. A dimensão das partículas foi determinada por difração Laser num granulómetro laser Coulter LS 230. A composiçáo mineralógica foi determinada nas fraçóes inferiores a $2 \mathrm{~mm}, 0,063 \mathrm{~mm}$, $0,032 \mathrm{~mm}$ e $0,0002 \mathrm{~mm}$, por difração de raios X (DRX), com um difratómetro de RX Philips PW 3710. Refira-se que as proporçóes minerais, determinadas com base no cálculo da área de reflexôes características, são semiquantitativas (MORE \& REYNOLDS, 1997). As análises químicas de sedimentos ( $\mathrm{Cu}$ e $\mathrm{Fe}$ ) foram realizadas no Laboratório de Biogeoquímica do Departamento de Ciências da Terra. A análise foi feita por absorção atómica, após ataque triácido (nítrico, clorídrico e fluorídrico) a $180^{\circ} \mathrm{C}$ e 15 bares, em microondas, seguido da complexação com ácido bórico. A precisão é superior $5 \%$.

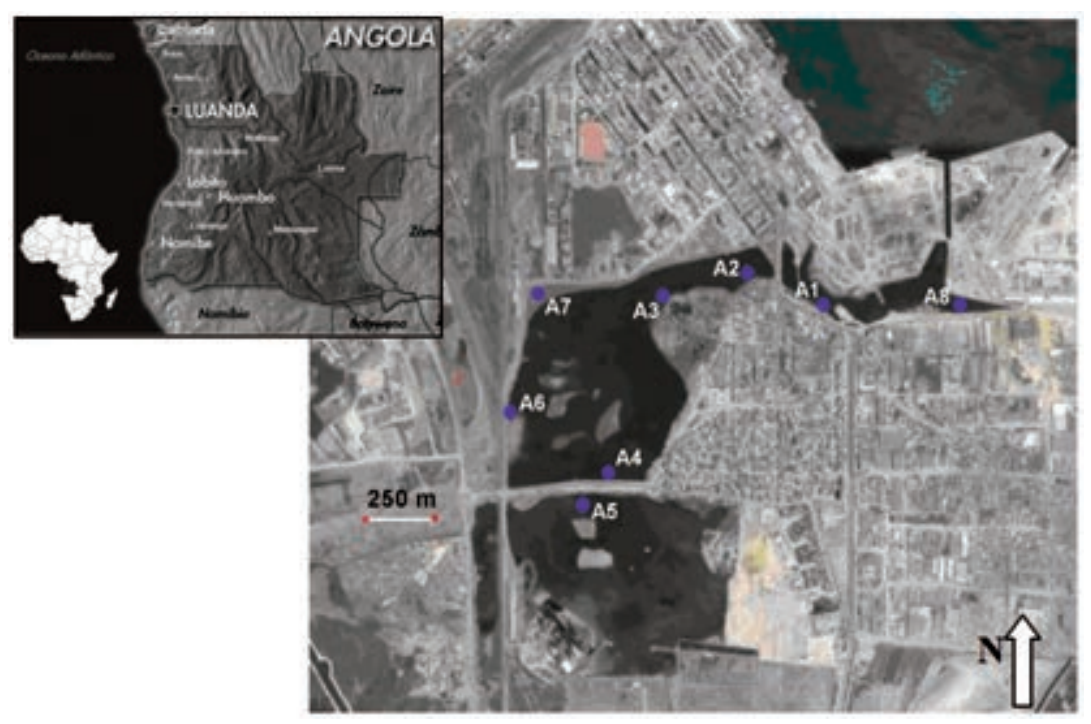

Fig. 1 - Localização das amostras estudadas. No mapa de enquadramento indica-se a localização da cidade de Lobito. 


\section{3 - Resultados}

As amostras de sedimentos são constituídas maioritariamente por areia (69-85\%), silte

(2 a 14\%) e argila (0,3 a 1,4\%) (tabela 1), com a média granulométrica a variar entre 0,1 a $5 \mathrm{~mm}$. Com base nas percentagens das várias fraçôes granulométricas e na média granulométrica é possível considerar 3 grupos de amostras: sedimentos grosseiros (A2 e A8), intermédios (A3, A4, e A5) e finos (A1, A6 e A7, com A6 a destacar-se por ser especialmente fina - Fig. 2).

Todas as amostras são maioritariamente constituídas por quartzo (38 a 82\%), feldspatos (10-19\%), filossilicatos (8-20\%), carbonatos (4 a 23\%) (tabela 1). No grupo dos carbonatos foi possível identificar calcite, dolomite, aragonite. Observaram-se ainda quantidades menores de halite, hematite, pirite e piroxena, que constituem o grupo dos outros minerais. As amostras grosseiras são as que apresentam maiores percentagens de quartzo (81 a 82\%). Em contrapartida, as amostras A1 e A6, integradas no grupo dos sedimentos mais finos, destacam-se por apresentarem menores quantidades de quartzo (38 a 45\%). Os sedimentos mais finos apresentam maiores quantidades de filossilicatos e de carbonatos (sobretudo A6).

$\mathrm{Na}$ fração inferior a $63 \mu \mathrm{m}$ os minerais mais comuns tanto podem ser os carbonatos ( 9 a $66 \%$ ) como o quartzo (10 a 34\%). Encontram-se também quantidades significativas de feldspatos ( 9 a 25\%) e de filossilicatos (5 a 23\%). Na fracção inferior a $32 \mu \mathrm{m}$ os minerais mais comuns também podem ser os carbonatos (14 a 65\%) ou o quartzo (10 a 33\%). As quantidades de filossilicatos são, regra geral, ligeiramente maiores que nas fraçóes inferiores a $32 \mu \mathrm{m}$ (11 a 23\%). No que respeita à fração argilosa, a mica-ilite (29 a 100\%) é o mineral mais bem representado na generalidade das amostras, geralmente seguido da caulinite (0-71\%). A amostra A6 é a única que apresenta maiores quantidades de caulinite do que de ilite. A amostra A7 também apresenta esmectite (9\%).

Tabela 1 - Características texturais e composicionais nos sedimentos das lagunas do Mangal do Lobito.

\begin{tabular}{|c|c|c|c|c|c|c|c|c|c|}
\hline & & A1 & A2 & A3 & A4 & A5 & A6 & A7 & A8 \\
\hline \multirow{4}{*}{ Granulometria } & Média $(\mathrm{mm})$ & 0,14 & 0,46 & 0,17 & 0,19 & 0,30 & 0,04 & 0,12 & 0,49 \\
\hline & $\%$ areia & 77,62 & 97,74 & 85,43 & 89,04 & 92,95 & 48,71 & 80,99 & 97,62 \\
\hline & $\%$ silte & 19,53 & 1,92 & 13,10 & 9,80 & 6,15 & 45,29 & 16,90 & 1,97 \\
\hline & $\%$ argila & 2,85 & 0,34 & 1,47 & 1,16 & 0,90 & 6,00 & 2,11 & 0,42 \\
\hline \multirow{2}{*}{ Química } & $\mathrm{Cu}(\mathrm{ppm})$ & 138,71 & 9,72 & 48,05 & 16,31 & 5,77 & 35,31 & 14,83 & 4,62 \\
\hline & $\mathrm{Fe}(\%)$ & 3,422 & 1,062 & 1,959 & 1,258 & 0,696 & 1,472 & 1,381 & 0,7 \\
\hline \multirow{6}{*}{$\begin{array}{l}\text { Mineralogia, } \\
\text { amostra total }\end{array}$} & Quartzo & 38 & 82 & 64 & 74 & 77 & 45 & 68 & 81 \\
\hline & Total Feldspato & 16 & 11 & 19 & 15 & 5 & 13 & 14 & 12 \\
\hline & Filossilicatos & 20 & 4 & 5 & 0 & 9 & 12 & 5 & 4 \\
\hline & Carbonatos & 8 & 2 & 2 & 5 & 9 & 29 & 5 & 2 \\
\hline & Hematite & 4 & 1 & 3 & 1 & 0 & 1 & 1 & 2 \\
\hline & Pirite & 7 & 0 & 4 & 1 & 0 & 0 & 2 & 0 \\
\hline \multirow{6}{*}{$\begin{array}{l}\text { Mineralogia, } \\
\text { fracção < } 63 \\
\mu \mathrm{m}\end{array}$} & Quartzo & 34 & 24 & 28 & 25 & 13 & 30 & 26 & 30 \\
\hline & Total Feldspato & 9 & 8 & 12 & 14 & 6 & 19 & 9 & 24 \\
\hline & Filossilicatos & 14 & 16 & 23 & 12 & 5 & 21 & 16 & 6 \\
\hline & Carbonatos & 9 & 20 & 12 & 15 & 66 & 11 & 42 & 34 \\
\hline & Hematite & 7 & 4 & 7 & 4 & 2 & 6 & 2 & 2 \\
\hline & Pirite & 5 & 7 & 5 & 4 & 1 & 12 & 5 & 4 \\
\hline \multirow{6}{*}{$\begin{array}{l}\text { Mineralogia, } \\
\text { fracção < } 32 \\
\mu \mathrm{m}\end{array}$} & Quartzo & 24 & 20 & 28 & 33 & 10 & 14 & 24 & 21 \\
\hline & Total Feldspato & 19 & 19 & 19 & 12 & 6 & 9 & 19 & 9 \\
\hline & Filossilicatos & 22 & 21 & 18 & 15 & 14 & 20 & 16 & 11 \\
\hline & Carbonatos & 14 & 25 & 16 & 23 & 65 & 52 & 20 & 52 \\
\hline & Hematite & 11 & 7 & 7 & 8 & 2 & 3 & 4 & 2 \\
\hline & Pirite & 6 & 2 & 7 & 4 & 2 & 3 & 4 & 2 \\
\hline
\end{tabular}


Os valores de parâmetros físico-químicos e alguns teores de espécies químicas determinados nas águas são dados na tabela 2 . Os valores de $\mathrm{pH}$ determinados na água das lagunas estão no intervalo de 8,17 a 9,08 (tabela 2), sendo superiores aos da água do mar e semelhantes aos das águas salinas (KRAUSKOPF \& BIRD, 1995). A salinidade das amostras de água também é frequentemente superior à da água do mar, variando entre 26,96 e 50,09 (tabela 2). O potencial de oxidação-redução medido nas águas amostradas na campanha de novembro varia entre $-56,1$ e 12,3 mV, tratando-se, portanto, de valores relativamente redutores (tabela 2 ).

Em termos de composição química, os teores de fosfato são tendencialmente mais baixos na campanha de novembro $(0,07$ e $0,42 \mathrm{mg} / \mathrm{L})$ e mais elevados na campanha de maio $(0,38$ e 1,25 mg/L) (Fig. 2A). Os teores de Cu, por sua vez, são mais altos na campanha de novembro $(103$ e $569 \mu \mathrm{g} / \mathrm{L})$ do que na de maio $(115$ e $250 \mu \mathrm{g} / \mathrm{L})$ (Fig. 2B). Os teores de ferro variaram entre 58 e $326 \mu \mathrm{g} / \mathrm{L}$, sendo semelhantes nas duas campanhas. Estes teores de $\mathrm{Fe}$ e $\mathrm{Cu}$ são, com exceção da amostra $\mathrm{A} 8$ para o $\mathrm{Fe}$, superiores ou muito superiores aos teores médios destes elementos, na água dos oceanos e na água dos rios (WINTER, 1998). Observa-se uma forte correlaçáo positiva $(\mathrm{r}=0,89)$ entre o $\mathrm{pH}$ e a salinidade (Fig. $3 \mathrm{~A})$ e há um decréscimo nos valores de nitritos com o aumento da quantidade de oxigénio dissolvido (Fig. 3B).

Tabela 2 - Valores de parâmetros físico-químicos e teores de espécies químicas nas águas das lagunas do Mangal do Lobito.

\begin{tabular}{|c|c|c|c|c|c|c|c|c|}
\hline & \multicolumn{8}{|c|}{ novembro de 2009} \\
\hline & A1 & A2 & A3 & A4 & A5 & A6 & A7 & A8 \\
\hline $\begin{array}{l}\text { Oxigénio } \\
\text { dissolvido (ppm) }\end{array}$ & 5,65 & 8,32 & 3,91 & 5,4 & 1,72 & 6,24 & 4,65 & 3,84 \\
\hline $\mathrm{pH}$ & 8,17 & 8,64 & 8,65 & 8,76 & 9,08 & 8,83 & 8,85 & 8,57 \\
\hline Temperatura $\left({ }^{\circ} \mathrm{C}\right)$ & 28,74 & 29,83 & 27,5 & 29,66 & 28,71 & 24,64 & 25,34 & 27,28 \\
\hline $\begin{array}{l}\text { Condutividade } \\
\text { elétrica }(\mathrm{mS} / \mathrm{cm})\end{array}$ & 45,16 & 60,94 & 57,95 & 76,51 & 78,05 & 64,03 & 57,43 & 56,13 \\
\hline TSD (ppt) & 29,52 & 39,07 & 38,72 & 49,21 & 51,04 & 45,13 & 39,95 & 37,66 \\
\hline Salinidade & 26,96 & 36,89 & 36,6 & 47,98 & 50,09 & 43,64 & 37,98 & 35,48 \\
\hline Eh & 12,3 & 6,9 & 11,1 & $-15,8$ & $-56,1$ & 7,4 & $-20,8$ & $-25,1$ \\
\hline $\begin{array}{l}\text { Oxigénio dissolvido } \\
\text { (\% saturação) }\end{array}$ & 84,9 & 134,5 & 60,8 & 92,5 & 29,4 & 96,2 & 70,3 & 59,0 \\
\hline $\mathrm{Cl}$ total $(\mathrm{mg} / \mathrm{L})$ & 0,09 & 0,08 & 0,05 & 0,09 & 0,09 & 0,08 & 0,07 & 0,05 \\
\hline $\mathrm{PO}_{4}^{2-}(\mathrm{mg} / \mathrm{L})$ & 0,11 & 0,42 & 0,1 & 0,11 & 0,07 & 0,24 & 0,35 & 0,19 \\
\hline $\mathrm{Cu}^{2+}(\mu \mathrm{g} / \mathrm{L})$ & 176 & 195 & 103 & 569 & 427 & 519 & 223 & 261 \\
\hline $\mathrm{Fe}^{2+}(\mu \mathrm{g} / \mathrm{L})$ & 141 & 124 & 220 & 159 & 127 & 204 & 326 & 58 \\
\hline
\end{tabular}

\begin{tabular}{|l|c|c|c|c|c|c|c|c|}
\hline $\begin{array}{l}\text { Oxigénio } \\
\text { dissolvido (ppm) }\end{array}$ & 3,93 & 4,57 & 4,21 & 3,83 & 9,1 & 8,73 & 6,63 & 3,71 \\
\hline Temperatura $\left({ }^{\circ} \mathrm{C}\right)$ & 27,04 & 25,83 & 28,5 & 28,7 & 30,7 & 29,6 & 26,34 & 27,13 \\
\hline $\begin{array}{l}\text { Oxigénio dissolvido } \\
(\% \text { saturaçáa) }\end{array}$ & 56,4 & 63,5 & 60,3 & 54,9 & 123,8 & 118,7 & 88,4 & 53,1 \\
\hline $\mathrm{NO}^{2-}(\mathrm{mg} / \mathrm{L})$ & 0,72 & 0,19 & 0,75 & 0,16 & 0,03 & 0 & 0,19 & 0,63 \\
\hline $\mathrm{Cl}_{\text {total }}(\mathrm{mg} / \mathrm{L})$ & 0,15 & 0,1 & 0,18 & 0,15 & 0,16 & 0,15 & 0,19 & 0,18 \\
\hline $\mathrm{PO}_{4}^{2-}(\mathrm{mg} / \mathrm{L})$ & 0,38 & 2,00 & 0,54 & 0,38 & 1,25 & 0,52 & 0,62 & 0,46 \\
\hline $\mathrm{Cu}^{2+}(\mu \mathrm{g} / \mathrm{L})$ & 218 & 152 & 156 & 250 & 115 & 116 & 150 & 156 \\
\hline $\mathrm{Fe}^{2+}(\mu \mathrm{g} / \mathrm{L})$ & 127 & 120 & 205 & 156 & 124 & 196 & 308 & 60 \\
\hline
\end{tabular}




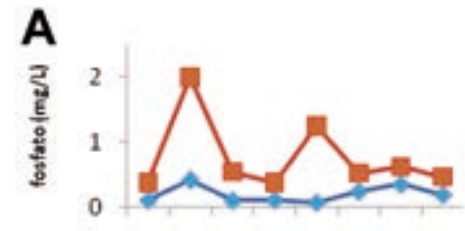

A1 A2 A3 A4 A5 A6 A7 A8 $\rightarrow$ Novembro $\rightarrow-$ Maio

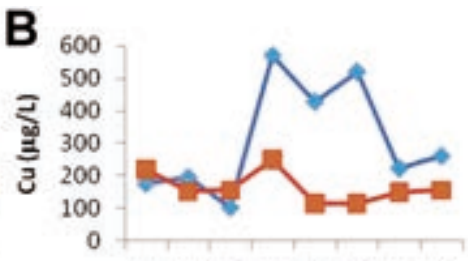

A1 A2 A3 A4 A5 A6 A7 A8

Fig. 2 - Diferenças entre os teores de fosfatos e Cu nas duas campanhas de amostragem.
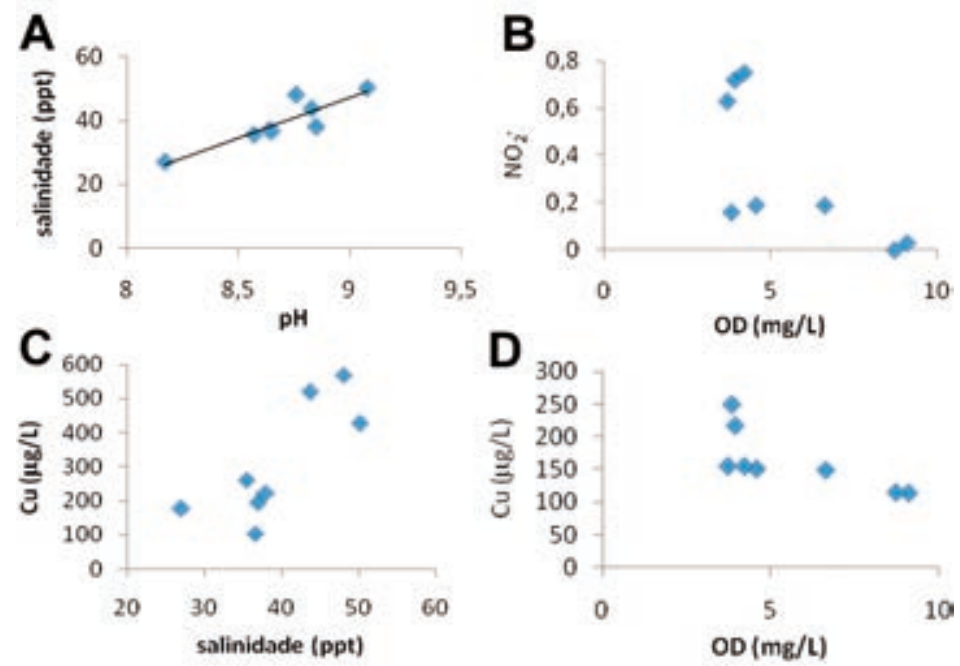

Fig. 3 - Algumas relaçôes entre parâmetros químicos da água. A. Correlação entre os valores de $\mathrm{pH}$ e de salinidade; $\mathrm{B}$. Relação entre os valores de oxigénio dissolvido (OD) e os teores de nitritos na campanha de maio. Teores de $\mathrm{Cu}$ em função da salinidade durante a campanha de novembro (C) e do OD durante a campanha de maio (D).

\section{4 - Discussão}

As características granulométricas e mineralógicas dos sedimentos e química da água apresentam alguma variabilidade espacial. Os sedimentos amostrados em locais mais próximos da linha de costa têm frequentemente dimensóes mais grosseiras, ao passo que as quantidades de carbonatos são frequentemente maiores em zonas mais interiores das lagunas (Fig. 4). Também a salinidade e o $\mathrm{pH}$ são maiores em posiçóes mais interiores das lagunas do que nos pontos mais próximos do Atlântico (Fig. 4), enquanto o oxigénio dissolvido é tendencialmente mais baixo em posiçóes mais interiores. Tal deve-se ao facto de, nas zonas mais interiores, a profundidade da água ser menor, o 
que leva a uma maior evaporação com o consequente aumento da salinidade e do pH e diminuição do oxigénio dissolvido.

Os teores em Fe e Cu da água são tendencialmente mais elevados nos setores mais interiores das lagunas (Fig. 4), onde a salinidade é também maior. Os teores especialmente elevados de $\mathrm{Cu}$ foram obtidos na campanha de amostragem de novembro, que antecedeu a época das chuvas. Nas amostras de maio, os teores de $\mathrm{Cu}$ surgem mais homogéneos ao longo do Mangal, não se encontrando diferenças espaciais significativas (Fig. 2). Estes factos indicam que a maior evaporação e o menor afluxo de água das chuvas promovem o enriquecimento em $\mathrm{Cu}$ durante a estação seca, em especial nos pontos com menor influência marinha. Já no que respeita aos fosfatos e nitritos, os valores são mais elevados após a estação das chuvas. Admite-se que o enriquecimento nestes compostos resulta da lixiviação e drenagem de campos agrícolas e áreas urbanas durante esta estação.

$\mathrm{O}$ enriquecimento em $\mathrm{Cu}$ em relação à água do mar e dos rios pode dever-se ao facto de ocorrerem mineralizações de cobre na regiáo, a leste do Lobito, drenadas pelo rio Catumbela e seus afluentes e referidas em GALVÃO \& SILVA (1972), ou à presença de cobre de origem antrópica. O cobre e ferro podem estar ligados à matéria orgânica, que é abundante nestas águas. Esta suposição é apoiada pelo facto de se observar um decréscimo nos teores de cobre com o aumento na quantidade de oxigénio dissolvido na campanha de novembro (Fig. 3D).
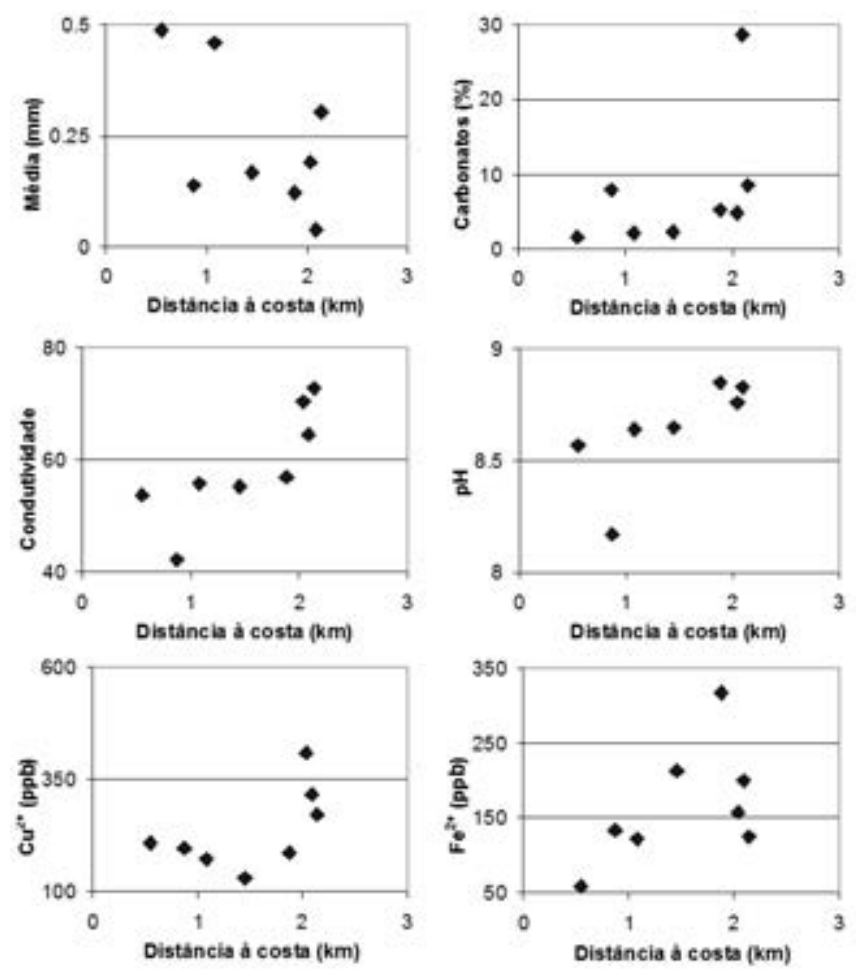

Fig. 4 - Caracterísiticas dos sedimentos (média granulométrica e percentagem de carbonatos) e das águas (condutividade elétrica, $\mathrm{pH}, \mathrm{Cu}$ e Fe) em função da distância à foz. 
Existe uma correlação negativa entre a percentagem de ferro na água e a média granulométrica dos sedimentos $(r=-0,72)$. Não se pode assumir, com segurança, que esta correlaçâo negativa se justifica por os sedimentos mais grosseiros apresentarem menores quantidades de minerais que integram ferro. Na verdade, ela pode justificar-se por as amostras mais grosseiras terem sido colhidas em posiçóes mais exteriores do Mangal, apresentando assim maior contribuição de água do mar que, como se afirmou acima, é tendencialmente mais pobre neste elemento que as águas das lagunas do Mangal. Também se verificaram correlaçóes negativas entre os teores de hematite e pirite nos sedimentos e os valores de $\mathrm{pH}(\mathrm{r}=-0,89$ e $\mathrm{r}=-0,72$, respetivamente) e condutividade elétrica $(\mathrm{r}=-0,72$ e $\mathrm{r}=-0,71$, respetivamente). Ou seja, os conteúdos em minerais de ferro no estado reduzido ou oxidado não favorecem, nem são favorecidos, de forma diferenciada, pelas condiçôes de oxidação. Este facto sugere que, quando se considera a amostra total, estes minerais são essencialmente detríticos e não estão a precipitar nas lagunas do Mangal do Lobito.

No que respeita à fração silto-argilosa observou-se uma correlação positiva entre o Eh e o conteúdo em hematite $(\mathrm{r}=0,85)$. Esta correlação pode estar associada à precipitação de hematite nas frações mais finas dos sedimentos em posições com ambiente mais oxidante. Para a fração silto-argilosa observaram-se ainda correlações quartzo-Eh $(\mathrm{r}=0,76)$, quartzo- $\mathrm{pH}(\mathrm{r}=-0,80)$, quartzo-salinidade $(\mathrm{r}=-0,76)$, filossilicatos-Eh $(\mathrm{r}=0,81)$ e carbonatos-Eh $(\mathrm{r}=0,93)$. Estas correlaçóes devem resultar de haver uma maior contribuição de partículas detríticas (sobretudo quartzo e filossilicatos) nos locais mais exteriores das lagunas, e de partículas associadas à precipitação de sais e ao desenvolvimento de organismos (carbonatos) nos locais mais interiores.

Finalmente, notou-se uma correlação negativa entre o $\mathrm{pH}$ da água e as proporções de $\mathrm{Cu}(\mathrm{r}=-0,79)$ e $\mathrm{Fe}(\mathrm{r}=-0,77)$ nos sedimentos. Uma vez que a matéria orgânica deve promover condiçôes ácidas, esta relação pode ser explicada por retenção de ferro e cobre através de processos de adsorção com aqueles componentes do sedimento. O conteúdo em matéria orgânica não foi assinalado, mas a cor e cheiro dos sedimentos sugerem que esta é muito comum, em particular nos materiais de grão mais fino.

\section{5 - Conclusốes}

As águas das lagunas do Mangal do Lobito são tendencialmente mais básicas, mais salinas e com menor oxigénio dissolvido que as águas do oceano. Os teores de ferro e cobre também são tendencialmente mais elevados em posições mais interiores do Mangal, em especial após a estação seca, sugerindo que a intensa evaporação durante este período é responsável pelo seu enriquecimento nas águas. As maiores concentraçôes de nitritos e fosfatos após a estação das chuvas podem ser explicadas por as águas pluviais promoverem a lavagem de campos agrícolas e áreas urbanas que envolvem o Mangal do Lobito, transportando quantidades significativas destes compostos, previamente acumulados durante o período seco, para as lagunas.

No que respeita aos sedimentos, estes têm frequentemente dimensóes mais grosseiras e apresentam maiores quantidades de grãos detríticos, nos locais com maior influência marinha, e de carbonatos, nos locais mais interiores das lagunas. A correlação entre os conteúdos de hematite na fração silto-argilosa e os valores de Eh das águas leva a crer que ocorre alguma precipitação de hematite nas frações de grão mais fino sob influência das condiçôes de oxidação. 
Agradecimentos - Agradece-se o apoio do Departamento de Ciências da Terra. Agradece-se a determinação de $\mathrm{Fe}$ e $\mathrm{Cu}$ nas amostras de sedimentos ao Prof. João Pratas.

\section{Referências Bibliográficas}

GALVÃO, C. F. \& SILVA, Z. (1972) - Notícia explicativa da Carta geológica do Lobito na escala 1:100.000 Série Geológica, e Minas de Angola, 39 p.

GUERREIRO, R. (2010) - Interaçôes água-sedimento no Mangal do Lobito. Dissertação de Mestrado, não publicada. Departamento de Ciências da Terra da Universidade de Coimbra, 54 p.

MORE, D. M \& REYNOLDS, R. C. (1997) - X-ray Diffraction and the identification and analysis of clay minerals. Oxford University Press, 378 p.

KRAUSKOPF, K. B. \& BIRD, D. K. (1995) - Introduction to Geochemistry. McGraw-Hill International Editions, $647 \mathrm{p}$.

WINTER, W. M. (1998) - Geochemistry, Chap. 15 - Oceans as a Chemical System. on-line edition. Acedido em: http://WWW.geo.cornell.edu/geology/classes/geo455/Chapters.HTML (consultado em 2010.07.01). 